\title{
Robotic Hand with Force Sensors
}

\author{
Moises Sanchez \\ Professor of English \\ Department of Industrial Maintenance Engineering \\ Universidad Tecnológica De Tlaxcala, México.
}

\author{
Jose Juan Sanchez, Edgar Hernandez \\ Students \\ Department of Industrial Maintenance Engineering \\ Universidad Tecnológica de Tlaxcala, México.
}

\begin{abstract}
The focus of this work was the realization of a prototype of a robotic hand, with the ability to mimic the movements of the human hand, and determine the force exerted by manipulating different electronic elements.

To carry out the process of elaboration, it developed in the SOLIDWORKS program the design of each part of hand (fingers, wrist and palm), taking into account the movements it can make, later with the help of a 3D printer and the CURA program, each designed part in SOLIDWORKS was printed to be assembled and the prototype of a human hand was obtained.

To achieve the operation of this prototype, ARDUINO programming software was used, that allowed to control the movement of the prototype by interacting with the human hand through the use of a glove with the implementation of flexo sensors on each of his fingers in such a way that the prototype could mimic the different movements that the human hand exerts, with the use of this glove.

Force sensors were subsequently implemented on each of the fingers of the prototype, so that they could determine the force exerted on each of these when manipulating different objects.

Finally, the prototype of the robotic hand was physically obtained, with the ability to manipulate objects and determine the force exerted on each of your fingers.
\end{abstract}

\section{INTRODUCTION}

The human hand basically performs two elementary functions as they are: mechanical or pressure function, in charge of the movement of the fingers and the sensitive function or better known as sense of touch, both are related since without the second it would be virtually impossible to measure the force when manipulating objects and therefore greater or lesser pressure would be exerted. [1]

A robotic hand consists of specific functions depending directly on the reason why it is developed, making some much more advanced than others in terms of complexity and functionality. The creation processes are very varied in order to ensure a good functioning in the area to be used and the uses that will be given to you later. [2]

For the development of such a model it was necessary to understand the motor functioning of the human limbs to reproduce them and get a "natural and precise movement".

The first point for the manufacture of a working prototype we had to devise the physical characteristics such as: the size of the hand, this was based on an average size of a male adult whose measurements are $189 \mathrm{~mm}$ (measure of fingers and palm) in addition to the material, as the care of the environment must be taken into account.

As the prototype model is for teaching use, the material was designated to be PLA, (Polylactic Acid), as it is a biodegradable material, which easily degrades into water and is made from PET.
Later, the parts of the hand (Fingers, palm, forearm) which were designed using CAD Software for 2D and 3D mechanical part modeling, also known as Solid Works, were manufactured from the PLA material, with the support of a $3 \mathrm{D}$ printer and the CURA program to continue the assembly of the prototype. [3]

It was necessary to implement electronic elements with the purpose to control the movements of the fingers, being these pressure sensors located on the fingers of our robotic hand, in addition to flexo sensors used in a glove to control movement, it was possible with five servomotors for the movement of each of the fingers.

Finally, the control of all these elements was achieved through the programing of the Arduino software and a couple of programming cards of type Arduino Nano and Arduino Uno.

\section{CREATING A ROBOTIC HAND}

For the creation of a robotic hand the software was used Solid Works for modeling 3D mechanical parts, it was chosen to create four different types of parts. The hand was composed with the palm of the hand, the wrist of the hand, the forearm and the fingers. This, so that the bending points were perfectly well articulated and that the hand has a more "natural" movement.

Analyzing the motor movement of the human hand, it was concluded that the dimensions of the palm should be $87 \mathrm{~mm}$ in the area of the fingers and openings of $6 \mathrm{~cm}$, separated by $15.75 \mathrm{~mm}$ from each other, in addition to a length of the area of the fingers to the $9 \mathrm{~mm}$ wrist and a thickness of $10 \mathrm{~mm}$, highlighting a support in the middle area of the right side for the thumb.

For the fingers, it was chosen to keep the same design for the experimental model, the dimensions were standardized, and for the thumb it was chosen that should keep only one part (Figure 1). [4]

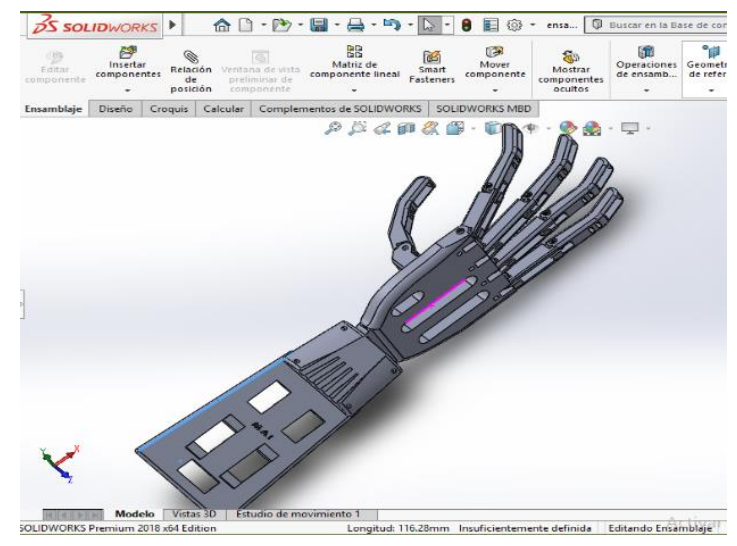

Figure 1 Prototype design. 
The microcontroller we designated to perform the functions and control of the hand was "ARDUINO".

Programming Arduino consists of translating into lines of code the automated tasks that we want to do by reading from the sensors and depending on the conditions of the environment to program the interaction with the outside world by means of actuators. [5]

The flexo sensors mounted on the glove are the ones that send the signal (Figure 2), the servo motors serve as actuators and signal receivers that send the flexo sensors to perform the motor movement on the robotic hand (Figure 3 and Figure 4).

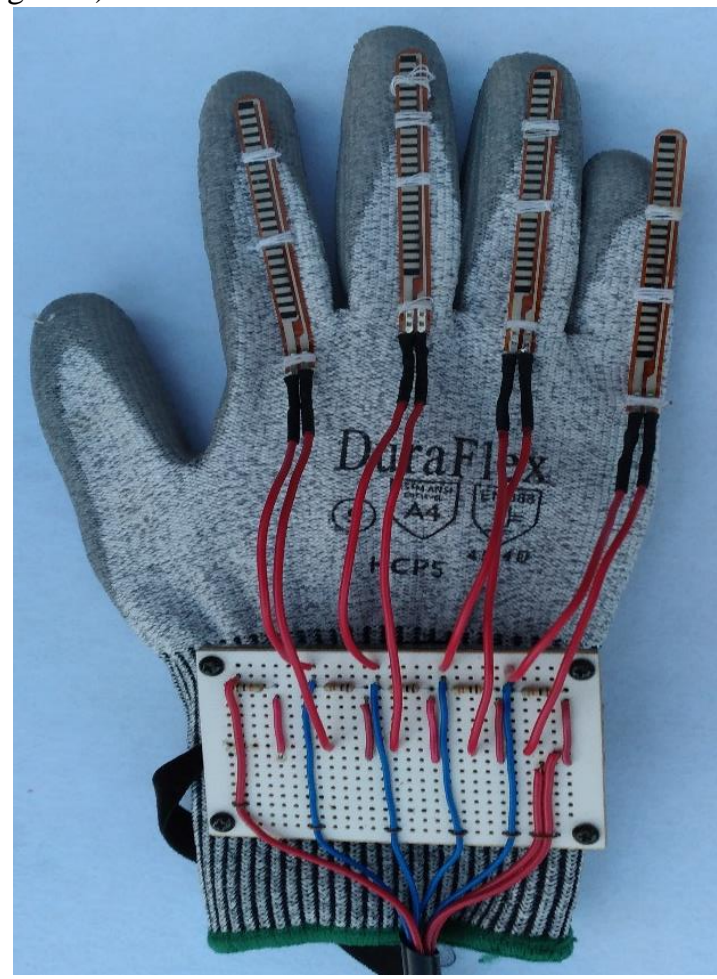

Figure 2 Glove to control the prototype.

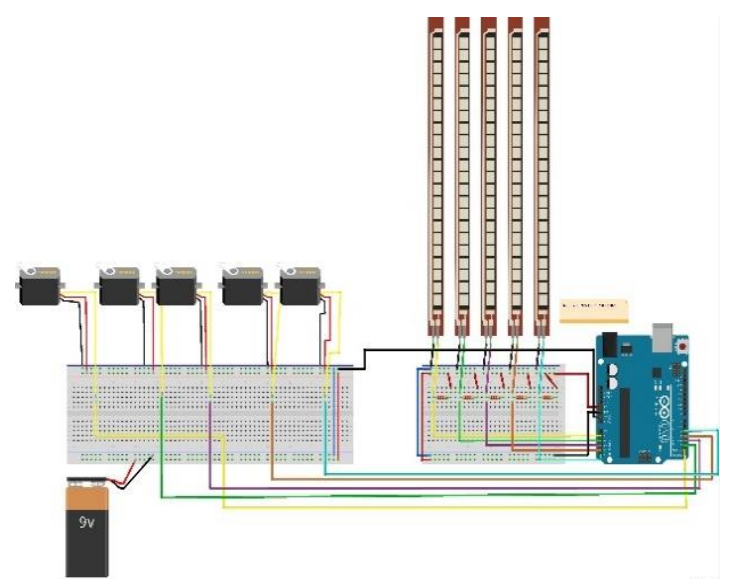

Figure 3 Connection diagram.

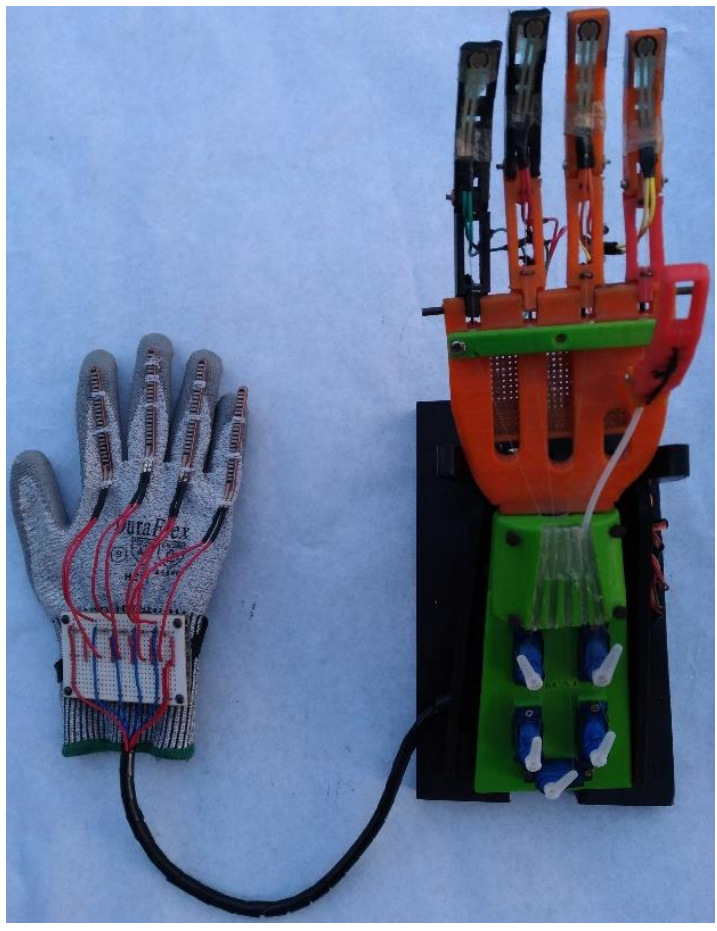

Figure 4 Prototype assembled. 
The code was developed in Arduino software for the control of the robotic hand (Figure 5).

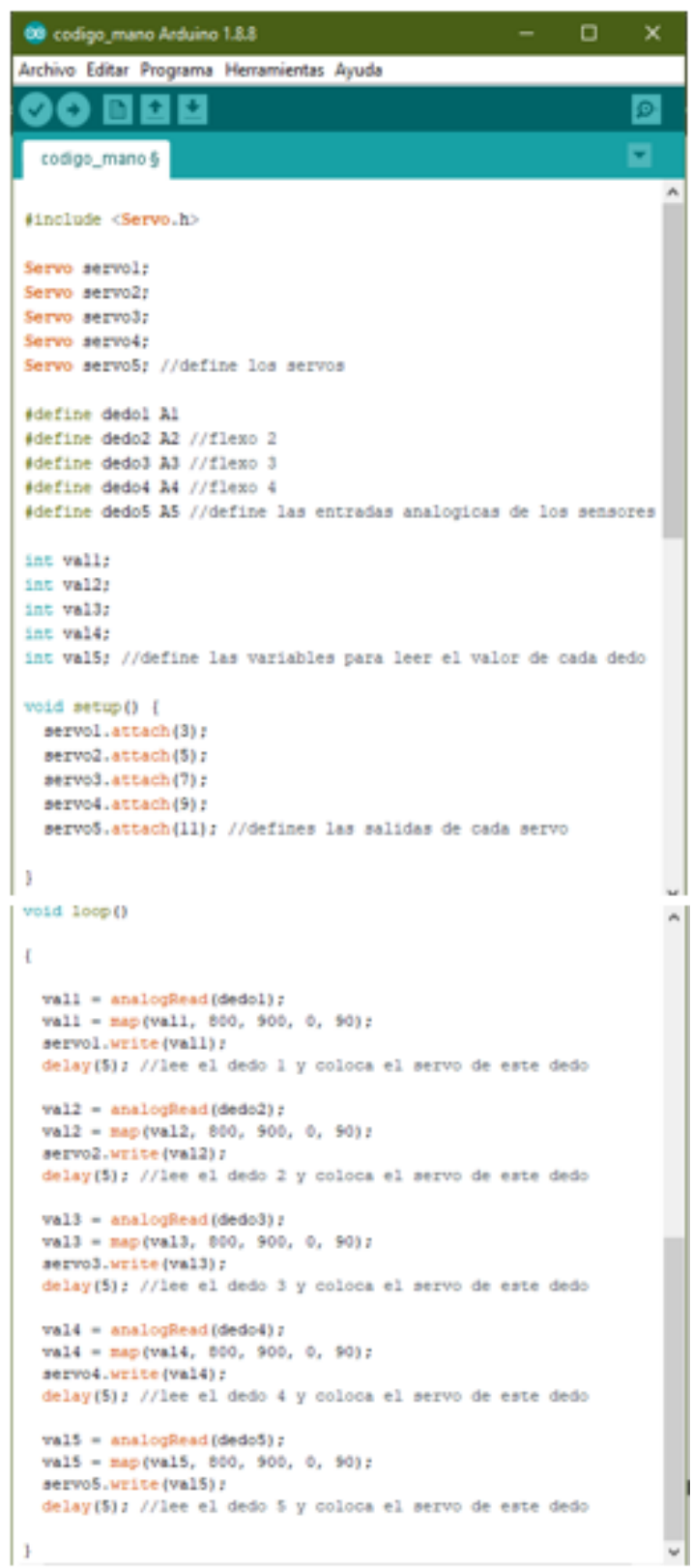

Figure 5 Code for glove-prototype interaction.

\section{PROGRAMMING AND IMPLEMENTATION OF PRESSURE -FORCE SENSORS}

It was chosen to acquire a Resistive Pressure Force Sensor to $4 \mathrm{~mm}$ Diameter (Fsr), because these sensors have the characteristics to support up to $1 \mathrm{~kg}$ and the Resistive Pressure Force Sensor are flexibles (Figure 6). [6]

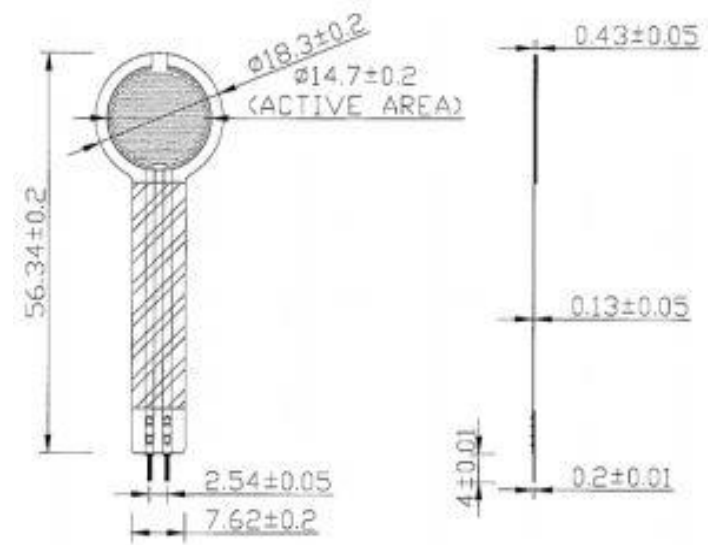

Figure 6 Force sensor.

Having the force resistive pressure sensor, we connected and put them on under the fingers of the robotic hand, holding them with an adhesive material called double-sided tape (Figure 7).

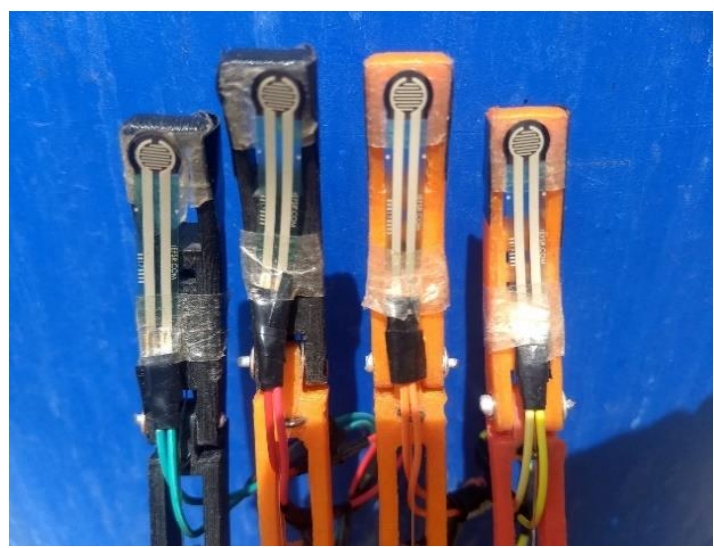

Figure 7 Placement of force sensors.

As all circuits and sensors must have a protection to prevent damage, the sensors were placed on top of the palm of the robotic hand. The terminals of the sensors were connected to the circuit. For these sensors, we use an "ARDUINO ONE" board (Figure 8).

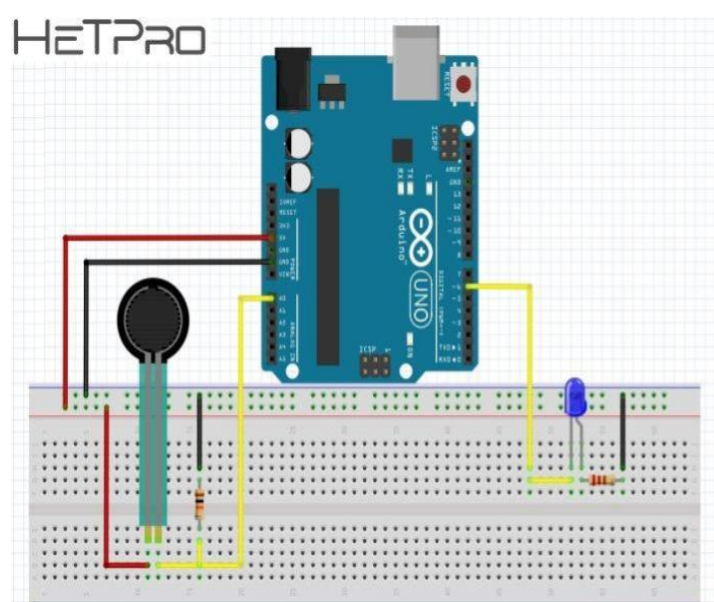

Figure 8 Use of ARDUINO ONE. 
The next step was the programming code, for the interpretation of data for each of the fingers, Arduino has a "serial monitor" that serves for different applications one of them is the visualization of the data send by the pressure force sensor (Figure 9).

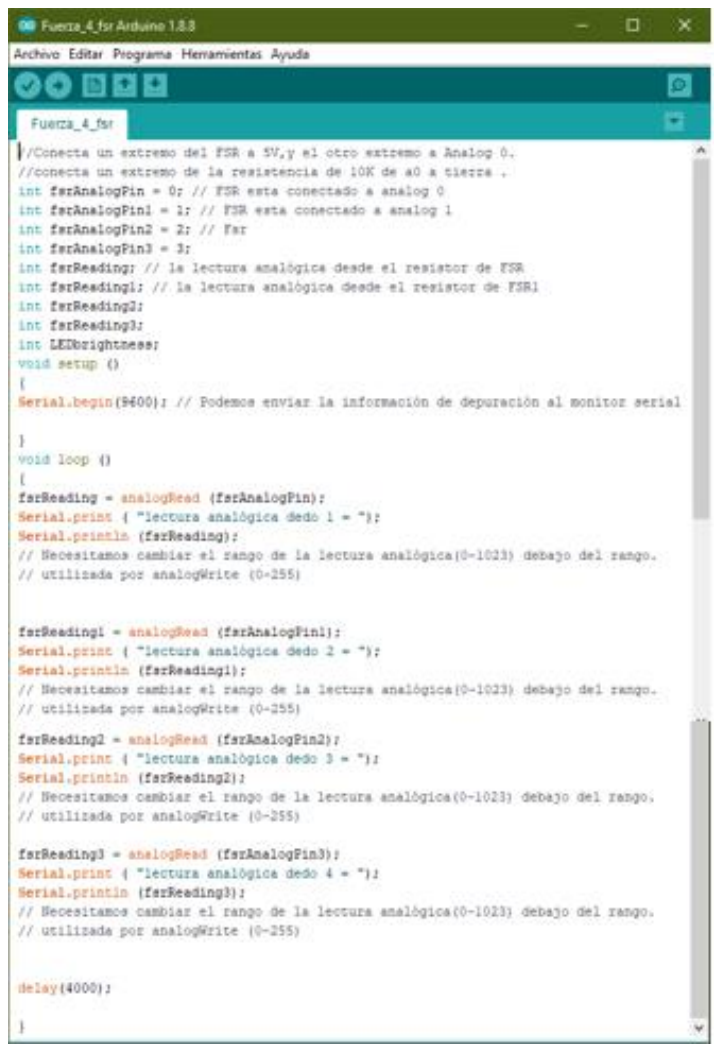

Figure 9 Code to control the force sensors.

The final steps were to tap cable, pin up well the sensors, to calibrate servo motors, to weld well to avoid aesthetic reason and to avoid failures.

\section{CONCLUSION}

The development of this project served to gain knowledge in programming aspects, development of electronic circuits, design and 3D printing.

The testing process of our robotic hand was correct, this model showed us the effectiveness of the programs created in conjunction with the proper mechanical functioning.
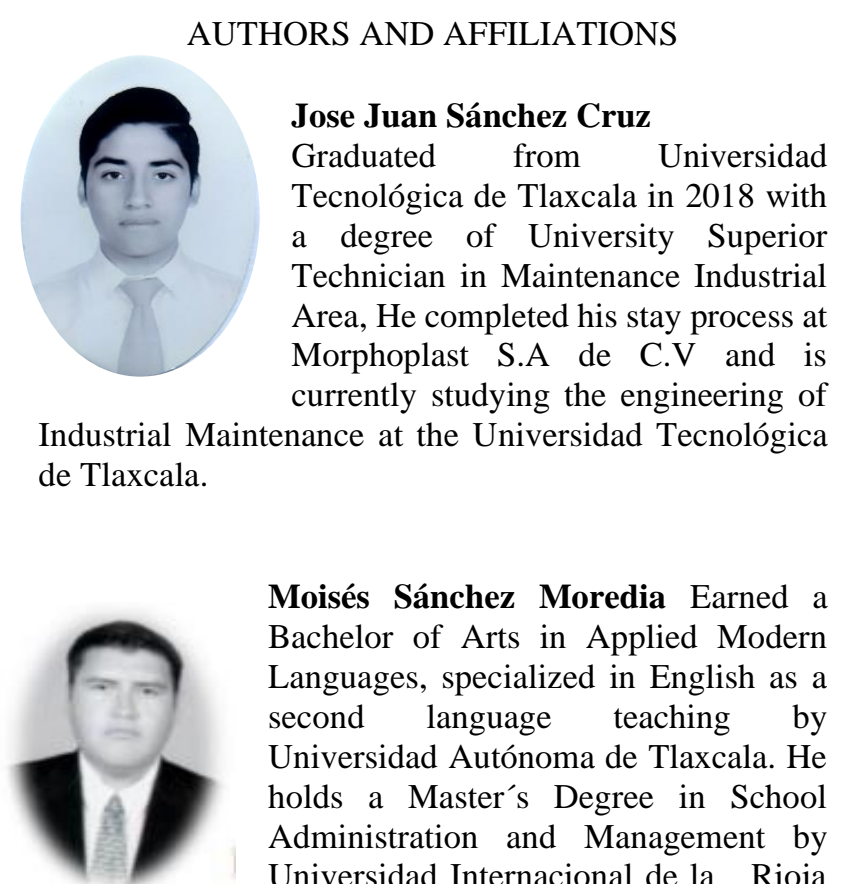

Moisés Sánchez Moredia Earned a Bachelor of Arts in Applied Modern Languages, specialized in English as a second language teaching by Universidad Autónoma de Tlaxcala. He holds a Master's Degree in School Administration and Management by Universidad Internacional de la Rioja (UNIR). From 2016 to 2018, He was the coordinator of the English area in Universidad Tecnológica de Tlaxcala where he currently teaches English in Industrial Maintenance Engineering.

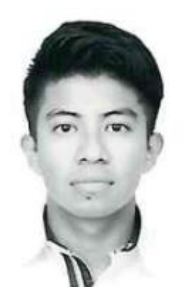

\section{Edgar Hernández Arenas}

Graduated from Universidad Tecnológica de Tlaxcala in 2018 with a degree of University Superior Technician in Maintenance Industrial Area, He completed his stay process at Empacadora Silva S.A de C.V and is currently studying the degree of Industrial Maintenance Engineering at the Universidad Tecnológica de Tlaxcala.

\section{REFERENCES}

[1] ANÍBAL O.B., "Robótica, Manipuladores y Robots Móviles", Marcombo S.A., 2001

[2] TAYLOR G.L., SCHARTZ R.J., "The Anatomy and Mechanics of the Human Hand", Artificial Limbs, 1995, Vol. 2

[3] SERGIO G.G., "Impresión 3D" Marcombo S.A., 1ra Edición, 2016.

[4] WILLIAM E. H., JOSEPH C.M., "Introduction to Solid Modeling", Mc Graw Hill, 13th Edition, 2017.

[5] JONATAHN O., HUGH B., "Practical Arduino", Technology in Action, 2009.

[6] ANTONIO S.R., FRANCISCO ANTONIO R.G., JUAN CARLOS R.N.," Guía Práctica de Sensores", Creaciones Copyright, 2010. 